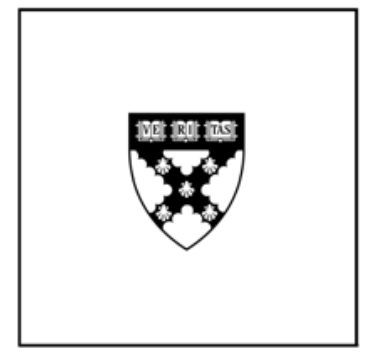

\title{
The Economic Crisis and Medical Care Usage
}

\author{
Annamaria Lusardi \\ Daniel Schneider \\ Peter Tufano
}

\section{Working Paper}

10-079

Rev. 1/24/2010 


\title{
The Economic Crisis and Medical Care Usage*
}

\author{
Annamaria Lusardi \\ Dartmouth College and NBER \\ Daniel Schneider \\ Princeton University \\ Peter Tufano \\ Harvard Business School, NBER, \\ and Doorways to Dreams Fund
}

\begin{abstract}
We use a unique, nationally representative cross-national dataset to document the reduction in individuals' usage of routine non-emergency medical care in the midst of the economic crisis. A substantially larger fraction of Americans have reduced medical care than have individuals in Great Britain, Canada, France, and Germany, all countries with universal health care systems. At the national level, reductions in medical care are related to the degree to which individuals must pay for it, and within countries are strongly associated with exogenous shocks to wealth and employment.
\end{abstract}

\footnotetext{
* Contact information: Annamaria Lusardi, Department of Economics, Dartmouth College, Hanover, NH 03755 (Annamaria.Lusardi@Dartmouth.edu); Daniel Schneider, Department of Sociology and Office of Population Research, Princeton University, Princeton, NJ 08544 (djschnei@princeton.edu); Peter Tufano, Harvard Business School, Soldiers Field, Boston, MA 02163 (ptufano@hbs.edu). This work was done in conjunction with the global market research firm, TNS and, we would like to thank Bertina Bus, Maria Eugenia Garcia-Neder, Ellen Sills-Levy, and Bob Neuhaus. The views expressed herein do not reflect those of TNS. Lusardi gratefully acknowledges financial support from Netspar. Schneider thanks the National Science Foundation and the Princeton Fellowship of Woodrow Wilson Scholars for financial support. Tufano thanks the HBS Division of Research and Faculty Development for financial support for this work.
} 
The global economic crisis, beginning roughly in July of 2007, took an historic toll on national economies and household finances around the world. Stock markets plummeted and unemployment rates rose markedly. What is the impact of such large shocks on individuals and their behavior? In this research, we examine the relationship between the crisis and medical care usage and show that the economic crisis had lead to reductions in individuals seeking care.

Economic distress' impact on medical care usage is mediated by its impact on individuals' bealth and their resources to pay for care. Previous research suggests that economic distress, especially unemployment, can have severe negative effects on health. ${ }^{1}$ In addition, individuals' willingness to seek care may decline with reduced financial resources to pay for it, as evidenced by a voluminous literature documenting a negative association between economic circumstances and health status and medical care usage. ${ }^{2}$ Evidence from developing countries also finds that individuals reduce their usage of medical care following economic crises. ${ }^{3}$ However, some recent studies find that health conditions may improve rather than decline in economic downturns, ${ }^{4}$ in part attributable to the additional time that reduced work hours or unemployment create for seeking routine medical care. ${ }^{5}$

Whether medical care increases or decreases in the face of the economic crisis is ultimately an empirical question. Our paper draws on new unique cross-national survey data to assess how the economic shocks brought on by the global economic crises affected the use of medical care in five developed economies: the United States, Great Britain, Canada, France, and Germany. We focus on changes in the utilization of routine medical care. This focus on routine medical care allows us to separate out the contrasting predictions of (a) reductions in care due to tighter resource constraints, (b) increases in care due to more time availability, and (c) increases in care due to severe deterioration in health. While the former 
two processes should be related to changes in routine care usage, the latter process should instead impact hospitalizations and other forms of acute care. ${ }^{1}$

If the primary barrier to not seeking routine care is having time to do so, we would expect to find that (1) the use of routine care should have increased since the economic crisis, (2) reductions in the usage of routine care should be negatively associated with unemployment, (3) but have no association with wealth loss, and (4) not vary substantially across countries. If instead the decision whether to seek care is constrained by financial resources, then (1) the use of routine care should have declined overall since the economic crisis, (2) reductions in the usage of routine care should be positively associated with unemployment and (3) have a positive association with wealth loss, and finally, (4) there should be differences across countries depending on the privately borne portion of the cost of care.

This last factor merits some additional explanation. While there is some cost to routine care in most of the countries under study, the amount of that cost varies considerably. While all individuals in Great Britain, Canada, France, and Germany are covered by national health care systems, only $85.3 \%$ of individuals in the United States are covered by health insurance. $^{6} \quad$ But, even in countries with universal coverage, individuals pay some medical care costs out of pocket. Using economy-wide data, in 2007 these payments accounted for $0.8 \%$ of GDP in France, $1.0 \%$ in Great Britain, 1.4\% in Germany, $1.5 \%$ in Canada, and $2.0 \%$ in the United States. ${ }^{6} \quad$ Among counties with national health care systems, France has the highest level of cost sharing for routine care; patients generally pay a $30 \%$ coinsurance for outpatient physician services and a 35\% coinsurance for prescription drugs. ${ }^{7} \quad$ In Germany, co-payments of 5 to 10 Euros are required for physician visits and outpatient medications. ${ }^{8}$ There is no cost sharing in Great Britain and Canada for routine 
care; however, prescriptions are not covered by the Canadian system. ${ }^{9}$ In the United States, the $15 \%$ of the population that is uninsured is fully responsible for the cost of routine care, and those who are covered still face copayments and coinsurance costs. Even in countries that provide "universal" health care, we might expect to find reductions in routine medical care usage following the economic crisis and to observe associations between such reductions and wealth losses and unemployment. As a general principal, we expect to find greater reductions in routine medical care usage in the countries where seeking medical care has a greater economic cost, e.g., the United States.

\section{Study Data ad Methods:}

Data Source: To assess how shocks to family resources affect medical care usage, we analyze a new data source, the TNS Global Economic Crisis survey, which we helped design and which was administered in June and July of 2009 in the United States, Great Britain, Canada, France, and Germany. The global market research firm TNS fielded the survey using an online questionnaire. In total 6,485 respondents were interviewed, including 2,148 in the United States, 1,001 in Great Britain, 1,132 in Canada, 1,097 in France, and 1,107 in Germany. The samples were designed to be nationally representative of each country's population 18-65 years of age and were subsequently weighted to reflect each nation's population. Nevertheless, it remains likely that our sample under-represents the most vulnerable groups of the population, including migrant workers and homeless people. This sampling will work against finding a result if the economic crisis has had the most severe effects on these individuals.

Medical Care Usage: Our survey assessed how respondents in each of the five countries changed their routine medical care usage. Respondents were asked, "Since the 
economic crisis have you increased, decreased, or kept the same trips to the doctor for routine medical and non-emergency treatment?" We chose this wording as opposed to asking about "preventive" care so as not to bias respondents toward selecting the socially acceptable answer. Self-reported measures of medical care usage are widely employed in the literature and have been shown to have good association with measures of care based on administrative and medical records. ${ }^{10}$

Economic Distress: To explore how changes in household economic conditions relate to changes in routine medical care usage, we use two other variables in the survey. First, we asked respondents to report any changes in the value of their financial assets since the onset of the crisis, indicating whether their assets increased in value (by $0-10 \%$ or greater than $10 \%$ ), stayed the same, or fell in value (by $0-10 \%, 10-29 \%, 30-50 \%$, or greater than $50 \%$ ). Respondents could also state that they did not know the answer or could refuse to answer. If these self-reported metrics are noisy, measurement error will bias against finding a relationship between shocks to wealth and reductions in routine medical care usage. Second, we collect information on employment status, using a variable that is set equal to 1 if the respondent is unemployed and looking for work and 0 otherwise. Data on unemployment were not collected for the Canadian sample, so analyses that include this variable are restricted to a sample of 4,405 respondents in the United States, Great Britain, France, and Germany.

Empirical analysis: We begin by presenting descriptive cross-country analyses of respondents' reports of changes in medical care usage and respondents' reports of wealth loss and unemployment. Next, we show the bi-variate association between our measure of reduction in routine medical care usage and our measure of change in wealth/unemployment. Finally, we estimate a set of multivariate regression models to 
examine whether the link between shocks to resources and changes in routine medical care usage persists after controlling for additional demographic characteristics (age, gender, and education), income, and wealth. In addition, we test whether the changes in usage are more pronounced in the United States, which does not have a national health care system and in which out-of-pocket health costs at the national level are the highest among the countries considered in this work.

We limit the sample to respondents who had complete data on our dependent variable as well as information on education, age, and gender, variables that we include in our multivariate regression model. We include dummy variables for respondents missing data on two key independent variables, our measure of income, and our measure of postcrisis wealth. This leaves us with a sample of 5,347 respondents. To test for robustness, we used alternative estimates that used multiple imputation to construct data for those reporting missing values or where we simply deleted the cases with missing data (Exhibit T1). These robustness tests yielded substantively similar results.

\section{Study Results:}

Reductions in Usage of Routine Care: Tabulating results by country shows substantial cross-national variation in post-crisis changes in routine medical care usage. Of American respondents, $26.5 \%$ reported reducing their use of routine medical care since the economic crisis (Exhibit 1). This proportion dwarfs the $5.6 \%$ of Canadian, $7.6 \%$ of British, $10.3 \%$ of German, and $12 \%$ of French respondents reporting such reductions. This ordering tracks with the level of privately-borne out-of-pocket routine medical costs across countries. Both absolutely and comparatively, Americans, who face higher out-of-pocket 
health care costs, reduced their routine medical care more than respondents in the other four countries.

Small minorities of respondents also reported increasing care, with between $5.4 \%$ and $7.9 \%$ of respondents giving that response. The fraction increasing care did not vary substantially across countries. We subtract the share increasing care from the share reporting decreasing care to generate a measure of net change in care. For most countries, we observe a net decrease in medical care. Specifically, on net, 19.5\% of Americans reduced their use of routine care (Exhibit 1). In Canada and Great Britain, where few copayments or coinsurance payments are required, there is essentially no change in aggregate country-level routine medical care usage $(-0.04 \%$ and $-0.31 \%$, respectively). In France and Germany, where larger copayments are required, we observe intermediate levels of net reductions in routine medical care usage, $6.6 \%$ and $3.6 \%$, respectively. This exercise further highlights the disparity in routine medical care reductions between the United States and the four comparison countries.

Changes in Wealth and Unemployment: Wealth losses were pervasive among households in the United States, with nearly 55\% of American respondents reporting some decline in their wealth since the start of the economic crisis and one-fifth reporting a decline of 30\% or larger (Exhibit 2). Losses were smaller in Great Britain, Canada, France, and Germany, with between $45 \%$ and $34 \%$ of respondents reporting any loss of wealth and between $13 \%$ and $9 \%$ reporting losses in excess of $30 \%$.

Unemployment increased sharply during the crisis. The share of respondents who reported being unemployed and looking for work was largest in Germany (14.4\%) and the United States (13.8\%), somewhat less in France (10.1\%), and lower still in Great Britain $(6.6 \%)$. These figures indicate that the economic crisis took a greater immediate economic 
toll on Americans than on individuals living in France, Canada, and Great Britain.

Economic Distress and Medical Care Usage: These negative shocks to wealth and employment are strongly associated with reductions in routine medical care (Exhibit 3). The greater the reported loss in wealth, the larger the net reductions in routine care across all countries. Similarly, net care reductions were more pronounced among the unemployed.

Exhibit 4 presents selected marginal effects from a multivarite probit regression model run on the pooled cross-national sample (the complete model specification is presented in Exhibit T2). Even after controlling for post-crisis wealth, income, education, age, and other characteristics, wealth loss is significantly associated with reductions in routine medical care usage (Model 1). As compared with respondents who reported no change in their wealth since the crisis, surveyed individuals who lost between $30 \%$ and $50 \%$ of their wealth are 23.3 percentage points more likely to have reduced routine medical care usage, and those who lost at least $50 \%$ of their wealth are 24.9 percentage points more likely to have reduced care. Unemployed respondents looking for work are 6.7 percentage points more likely to have reduced routine care than others (Model 2). In other words, we see substantial reductions in routine medical care usage as a result of shocks resulting from the economic crisis, even after accounting for many household characteristics.

We also find that reductions in routine medical care were higher for the young and for those with lower incomes. In particular, relative to those aged 50 to 65 , respondents aged 16-24, 25-34 and 35-49 were 11.7, 6.8 and 4.6 percentage points more likely to reduce care respectively. Relative to individuals in the top income quartile, those in the bottom quartile, $26-50^{\text {th }}$ percentile, and 51 to $75^{\text {th }}$ percentile were $5.7,5.9$, and 2.0 percentage points more likely to reduce medical care respectively. ${ }^{11}$ 
Exhibit 5 reports selected results from a multi-nomial probit regression that jointly analyzes the determinants of those who decreased, kept the same, and increased routine medical care usage (the complete model specification is presented in Exhibit T3). While there are few statistically significant associations between changes in wealth or unemployment and increases in care (relative to no change in care), we continue to find large and statistically significant associations between reductions in care and wealth loss and unemployment. Focusing on wealth loss, respondents who lost between $30 \%$ and $50 \%$ of their wealth are 22.8 percentage points more likely to have reduced routine medical care usage, and those who lost at least $50 \%$ of their wealth are 23.1 percentage points more likely to have reduced care as opposed to keeping care the same relative to those whose wealth is unchanged. Unemployed respondents 6.7 percentage points more likely to reduce care than those who are not unemployed. These estimates of the marginal effects of wealth loss and unemployment are quite similar to those from the simpler bi-variate model discussed above.

Exhibit 4 also reports country fixed effects that capture the levels of reduction in routine medical care use by country, after holding household factors constant. Reductions in care were far greater in the United States than elsewhere, even after controlling for household characteristics. Compared with Great Britain, Americans were 16 percentage points more likely to reduce care. In contrast, French and German respondents were only 4.5 and 3.8 percentage points more likely, respectively, to reduce care than British respondents, while Canadian respondents were actually 3 percentage points less likely to reduce care. As with the descriptive statistics reported in Exhibit 1, the magnitude of these country effects aligns with the size of the required coinsurance and copayments for routine care.

Finally, we tested whether the strength of the relationships between our markers of 
economic distress (wealth loss and unemployment) and reductions in care varied by country. We first re-estimated our models separately by country and found strong relationships between wealth loss and unemployment and reductions in medical care usage in each country, with the exception of Great Britain (Exhibit T4). To test whether the relationship between routine heath care usage and wealth loss and unemployment varies among countries, we also re-estimated our models to include interaction terms between country dummies and each of the two variables measuring economic shocks. Generally, the relationship between wealth loss and reduction in routine medical care levels is statistically indistinguishable in the United States as compared to the other four countries. Similarly, there is no variation in the relationship between unemployment and reduction in use of routine care in the United States as compared with the other four countries (Exhibit T5). This result aligns with previous research that finds similar income gradients in access to care in the United States and Canada. ${ }^{12}$

\section{Discussion:}

We find strong evidence that the economic crisis-manifested in job and wealth losses-has led to reductions in the use of routine medical care. More than a quarter of Americans reported reducing their use of such care as did between $5 \%$ and $12 \%$ of Canadian, French, Germany, and British respondents. These cross-national differences align with differences in the out-of-pocket costs of care across countries. Moreover, reductions in routine care are strongly related to wealth and job losses, showing that households in economic distress were more likely to reduce medical care usage. In contrast, we find that relatively few households reported increasing medical care and that there was no significant relationship between unemployment and increased use of medical care. 
This research confirms that resource constraints have large impacts on the usage of routine medical care. Further, the across-the-board reduction in medical care usage by Americans may speak to behavioral changes that reflect the national psyche broadly. The economic crisis in the United States-deeper and more widespread than elsewhere-may have touched the population at large, perhaps via negative expectations about the future. Furthermore, the cutbacks in health care usage by people losing wealth or jobs, even in countries with "universal" systems, may reflect that seeking care entails not only out-ofpocket expenses, but also costs of time away from work or job hunting.

President Obama has embarked on twin efforts to bring the United States out of the severe economic crisis and make reforms to the American health care system. We show that these are by no means separate areas of policy; the economic distress brought on by the crisis is related to large reductions in routine medical care usage. Historical demography and economics has shown that famines and epidemics that have short-run effects on health and well-being often have long-term consequences. ${ }^{13}$ While we cannot observe long-term consequences of the reductions in use of routine medical care that survey participants reported to us, today's penny-pinching might well lead to tomorrow's undetected illness and the more-distant future's reduced individual health and well-being. 


\section{ENDNOTES}

1. Catalano R. Health, Medical Care, and Economic Crisis. N Engl J Med. 2009 Feb 19; 360(8): 749-751; and Eliason M, Storrie D. Lasting or Latent Scars? Swedish Evidence on the Long-Term Effects of Job Displacement. Journal of Labor Economics. 2006 Oct 1; 24(4): 831-856; and Eliason M, Storrie D. Job loss is bad for your health Swedish evidence on cause-specific hospitalization following involuntary job loss. Social Science \& Medicine. 2009 Apr; 68(8): 1396-1406; and Eliason M, Storrie D. Does Job Loss Shorten Life? J. Human Resources. 2009 Apr 1; 44(2): 277-302; and Sullivan D, Wachter TV. Job Displacement and Mortality: An Analysis Using Administrative Data. Quarterly Journal of Economics. 2009; 124(3): 1265-1306.

2. Williams DR, Collins C. US Socioeconomic and Racial Differences in Health: Patterns and Explanations. Annu. Rev. Sociol. 1995 8; 21(1): 349-386; and Feinstein JS. The Relationship between Socioeconomic Status and Health: A Review of the Literature. The Milbank Quarterly. 1993; 71(2): 279-322.

3. Musgrove P. The economic crisis and its impact on health and health care in Latin America and the Caribbean. Int J Health Serv. 1987; 17(3): 411-441; and Waters H, Saadah F, Pradhan M. The impact of the 1997-98 East Asian economic crisis on health and health care in Indonesia. Health Policy Plan. 2003 Jun 1; 18(2): 172-181; and Yang $\mathrm{B}$, Prescott N, Bae E. The impact of economic crisis on health-care consumption in Korea. Health Policy Plan. 2001 Dec 1; 16(4): 372-385.

4. Ruhm CJ. Are Recessions Good for Your Health?. Quarterly Journal of Economics. 2000 May 1;115(2):617-650; and Ruhm CJ. A healthy economy can break your heart. Demography. 2007 Nov; 44(4): 829-848.

5. Neumayer E. Recessions lower (some) mortality rates:: evidence from Germany. Social Science \& Medicine. 2004 Mar; 58(6): 1037-1047.

6. Organization for Economic Co-Operation and Development, OECD Health Data 2009 [Computer Software and File]. Paris: Organization for Economic Co-operation and Development/Institute for Research and Information in Health Economics [Producers], Paris: Organization for Economic Co-operation and Development [Distributor], 2009. URL: http://new.sourceoecd.org.

7. Lundy, J., B. Finder, "Cost Sharing for Health Care: France, Germany, and Switzerland." (Henry J. Kaiser Family Foundation, 2009)

8. Commonwealth Fund, Descriptions Of Health Care Systems: Denmark, France, Germany, The Netherlands, Sweden, And The United Kingdom (2008).

9. Schoen C, Doty MM. Inequities in access to medical care in five countries: findings from the 2001 Commonwealth Fund International Health Policy Survey. Health Policy. 2004 Mar;67(3):309-322. 
10. Bhandari A, Wagner T. Self-Reported Utilization of Health Care Services: Improving Measurement and Accuracy. Med Care Res Rev. 2006 Apr 1; 63(2): 217-235.

11. Based on results from a probit regression model with controls for changes in wealth, unemployment, wealth, gender, education and country-fixed effects. Full model results are reported in Model 1 of Exhibit 2 of the technical appendix.

12. Lasser KE, Himmelstein DU, Woolhandler S. Access to Care, Health Status, and Health Disparities in the United States and Canada: Results of a Cross-National PopulationBased Survey. Am J Public Health. 2006 Jul 1;96(7):1300-1307; and Katz SJ, Hofer TP. Socioeconomic Disparities in Preventive Care Persist Despite Universal Coverage: Breast and Cervical Cancer Screening in Ontario and the United States. JAMA. 1994 Aug 17; 272(7): 530-534.

13. e.g. Almond D. Is the 1918 Influenza Pandemic Over? Long Term Effects of In Utero Influenza Exposure in the Post-1940 U.S. Population. Journal of Political Economy. 2006; 114(4): 672-712. 


\section{EXHIBITS:}

Exhibit 1: Changes in the Utilization of Routine Medical Care Since the Economic Crisis, United States, Great Britain, Canada, France, and Germany (Percent of Respondents) (Authors' calculations from the TNS Global Economic Crisis Survey, 2009)

\begin{tabular}{lrrrrr}
\hline \multirow{2}{*}{ Country } & \multicolumn{3}{c}{ Changes in Utilization of Routine Health Care Since the Crisis } & N \\
\cline { 2 - 5 } & Reduce & Same & Increase & $\begin{array}{r}\text { Net Change } \\
\text { (Reduce-Increase) }\end{array}$ & N \\
\hline United States & 26.5 & 66.5 & 7.0 & 19.5 & 1901 \\
France & 12.0 & 82.7 & 5.4 & 6.6 & 868 \\
Germany & 10.3 & 83.0 & 6.7 & 3.6 & 879 \\
Canada & 5.3 & 89.3 & 5.4 & 0.0 & 1032 \\
Great Britain & 7.6 & 84.4 & 7.9 & -0.3 & 757 \\
\hline 5 Country Avg & 15.2 & 78.3 & 6.6 & 5.9 & 5437 \\
\hline
\end{tabular}


Exhibit 2. Economic Characteristics of Respondents, United States, Great Britain, Canada, France, and Germany (Percent of Respondents) (Authors' calculations from the TNS Global Economic Crisis Survey, 2009)

\begin{tabular}{|c|c|c|c|c|c|}
\hline Economic Attributes & $\begin{array}{l}\text { United } \\
\text { States }\end{array}$ & France & Germany & Canada & $\begin{array}{l}\text { Great } \\
\text { Britain }\end{array}$ \\
\hline \multicolumn{6}{|l|}{ Change in Wealth } \\
\hline incr $>=10 \%$ & 7.8 & 9.9 & 9.3 & 9.0 & 7.8 \\
\hline incr $<10 \%$ & 10.6 & 13.0 & 11.4 & 14.0 & 7.8 \\
\hline about same & 26.8 & 42.9 & 42.8 & 38.5 & 39.0 \\
\hline decr $<10 \%$ & 13.0 & 10.7 & 15.1 & 14.4 & 14.8 \\
\hline decr $10 \%$ to $29 \%$ & 21.5 & 11.8 & 8.8 & 15.6 & 19.5 \\
\hline decr $30 \%$ to $50 \%$ & 11.3 & 6.3 & 7.7 & 4.9 & 5.4 \\
\hline decr $>50 \%$ & 9.1 & 5.5 & 4.9 & 3.6 & 5.8 \\
\hline \multicolumn{6}{|l|}{ Employment } \\
\hline Unemployed and Seeking Work & 13.8 & 10.1 & 14.4 & -- & 6.6 \\
\hline $\mathrm{N}$ & 1901 & 868 & 879 & 1032 & 757 \\
\hline \multicolumn{6}{|l|}{ Notes: } \\
\hline 1. Data on unemployment is not available $f$ & However, & ondents are & ed in the tabul & of all other $v$ & \\
\hline
\end{tabular}


Exhibit 3: Economic Loss and Reductions in Medical Care. Bi-variate Association between Changes in Wealth and Reductions in Routine Medical Care and between Unemployment and Reductions in Medical Care (Authors' calculations from the TNS Global Economic Crisis Survey, 2009)

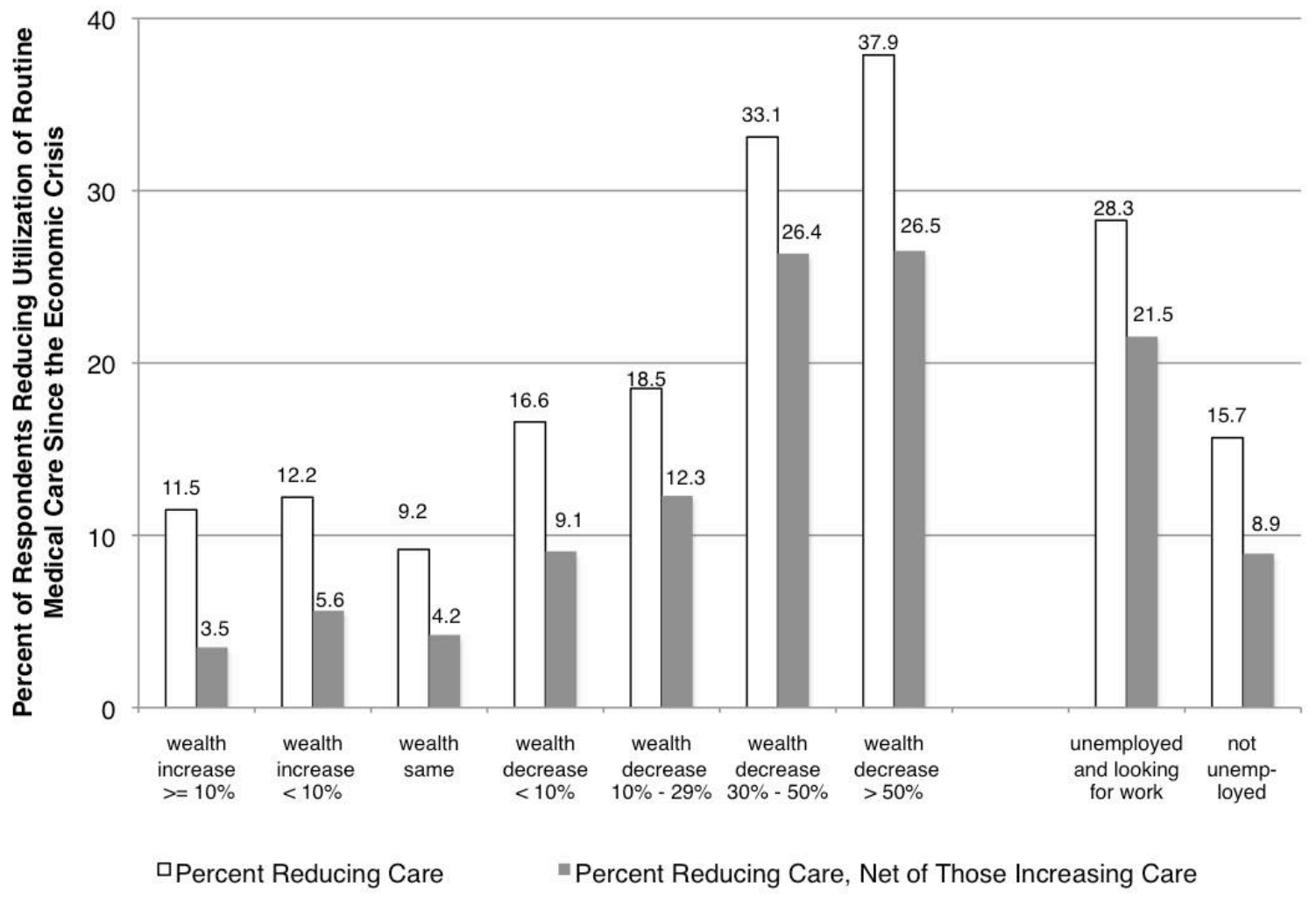


Exhibit 4: Relationship Between Reduction in Routine Medical Care Following the Crisis and Changes in Wealth and Unemployment, Marginal Effects (standard errors) from Probit Regression, United States, Great Britain, Canada, France, and Germany (Authors' calculations from the TNS Global Economic Crisis Survey, 2009)

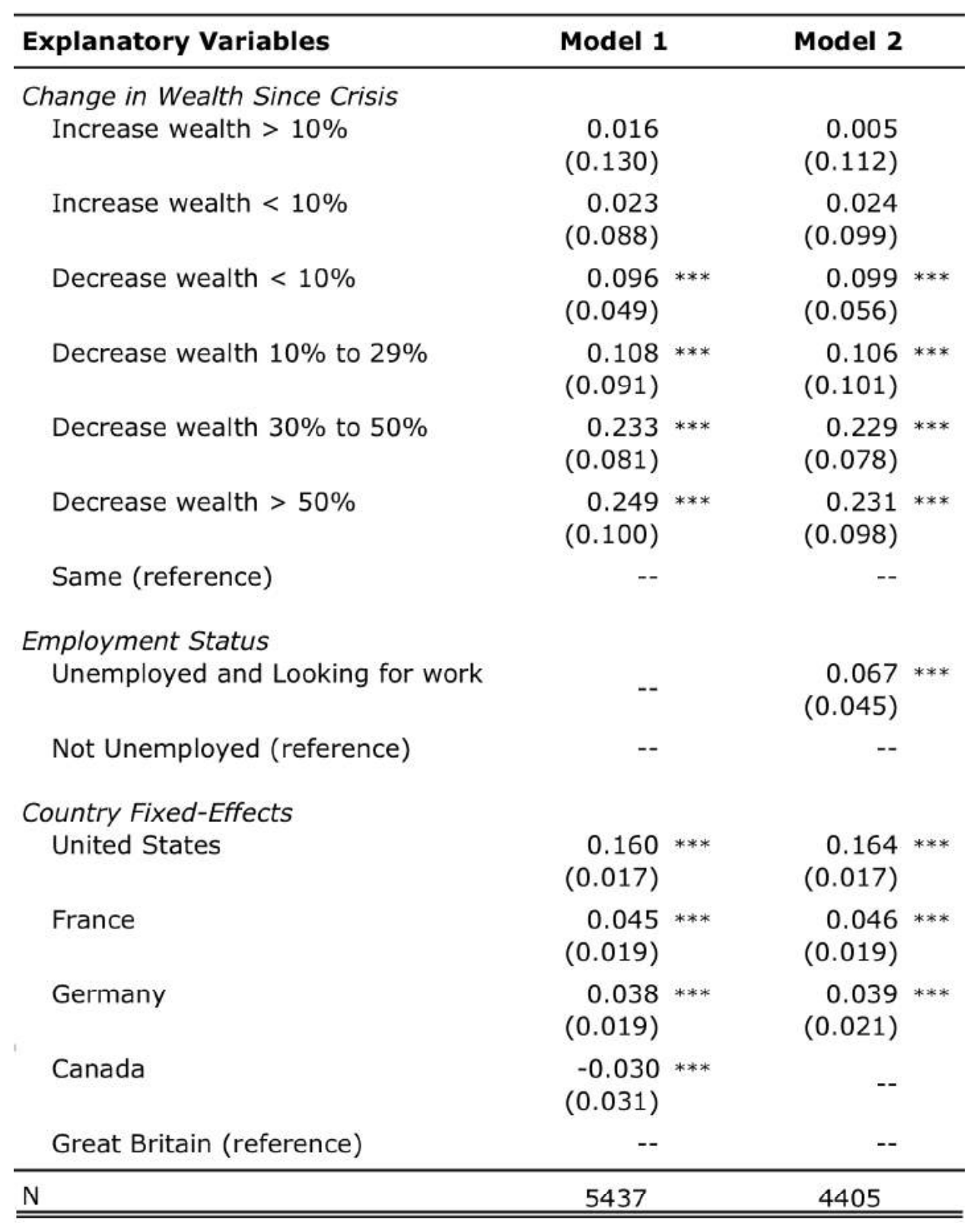

* $\mathrm{p}<0.05, * * \mathrm{p}<0.01, * * \mathrm{p}<0.001$

Notes:

1. Both models include controls for age, income, wealth, gender, and country.

2. Standard errors are adjusted for clustering at the country-level.

3. Regressions are estimated using individual sample weights.

4. Sample limited to respondents with complete data on the dependent variable, age, education, and gender. Dichotomous indicators are included for respondents missing data on income, wealth, and changes in wealth.

5. Model 2 excludes all Canadian respondents because no unemployment data is available for Canada. 
Exhibit 5: Relationship Between Reductions in Routine Medical Care (Relative to Same) and Increases in Routine Medical Care (Relative to Same) and Changes in Wealth and Unemployment, Marginal Effects from Multinomial Probit Regression, United States, France, Germany, and Great Britain (Authors' calculations from the TNS Global Economic Crisis Survey, 2009)

\begin{tabular}{|c|c|c|c|}
\hline \multirow[t]{2}{*}{ Explanatory Variables } & $\begin{array}{c}\text { Increase } \\
\text { Routine Care } \\
\text { (relative to } \\
\text { Same) } \\
\end{array}$ & \multicolumn{2}{|c|}{$\begin{array}{c}\text { Decrease } \\
\text { Routine Care } \\
\text { (relative to } \\
\text { Same) }\end{array}$} \\
\hline & [1] & [2] & \\
\hline \multicolumn{4}{|l|}{ Country-Level Fixed Effects } \\
\hline United States & -0.014 & 0.165 & $* * *$ \\
\hline France & $-0.031 * *$ & 0.045 & $* * *$ \\
\hline Germany & $-0.016 * * *$ & 0.039 & $* * *$ \\
\hline Great Britain (reference) & -- & -- & \\
\hline \multicolumn{4}{|l|}{ Change in Wealth Since Crisis } \\
\hline Increase wealth $>10 \%$ & 0.013 & 0.003 & \\
\hline Increase wealth $<10 \%$ & 0.022 & 0.023 & \\
\hline Decrease wealth $<10 \%$ & $0.030 *$ & 0.099 & $* * *$ \\
\hline Decrease wealth $10 \%$ to $29 \%$ & 0.004 & 0.107 & $* * *$ \\
\hline Decrease wealth $30 \%$ to $50 \%$ & 0.012 & 0.228 & $* * *$ \\
\hline Decrease wealth $>50 \%$ & $0.051 * * *$ & 0.231 & $* * *$ \\
\hline Same (reference) & -- & -- & \\
\hline \multicolumn{4}{|l|}{ Employment Status } \\
\hline Unemployed and Looking for work & 0.000 & 0.067 & $* * *$ \\
\hline Not Unemployed (reference) & -- & -- & \\
\hline $\mathrm{N}$ & & & \\
\hline
\end{tabular}

$* \mathrm{p}<0.05, * * \mathrm{p}<0.01, * * \mathrm{p}<0.001$

Notes:

1. Model includes controls for age, income, wealth, gender, and country.

2. Standard errors are adjusted for clustering at the country-level.

3. Regressions are estimated using individual sample weights.

4. Sample limited to respondents with complete data on the dependent variable, age, education, and gender. Dichotomous indicators are included for respondents missing data on income, wealth, and changes in wealth.

5. Model excludes all Canadian respondents because no unemployment data is available for Canada. 


\section{TECHNICAL APPENDIX:}

Exhibit T1: Robustness of Regression Results to Alternative Treatments of Missing Data, Coefficients from Probit Regressions, United States, France, Germany, and Great Britain (Authors' calculations from the TNS Global Economic Crisis Survey, 2009)

\begin{tabular}{|c|c|c|c|c|}
\hline \multirow[t]{2}{*}{ Explanatory Variables } & $\begin{array}{l}\text { Multiple } \\
\text { Imputation }\end{array}$ & $\begin{array}{c}\text { Dummy } \\
\text { Variable }\end{array}$ & \multicolumn{2}{|c|}{$\begin{array}{l}\text { List-Wise } \\
\text { Deletion }\end{array}$} \\
\hline & [1] & [2] & \multicolumn{2}{|l|}{ [3] } \\
\hline \multicolumn{5}{|l|}{ Country-Level Fixed Effects } \\
\hline United States & $0.702 * * *$ & $0.690 * * *$ & 0.743 & $* * *$ \\
\hline France & $0.194 * *$ & $0.192 * * *$ & 0.212 & $* \ldots *$ \\
\hline Germany & $0.095 * * *$ & $0.165 * * *$ & 0.353 & $* * *$ \\
\hline Great Britain (reference) & - & - & $\cdots$ & \\
\hline \multicolumn{5}{|l|}{ Change in Wealth Since Crisis } \\
\hline Increase wealth $>10 \%$ & 0.056 & 0.021 & -0.035 & \\
\hline Increase wealth $<10 \%$ & 0.068 & 0.102 & 0.078 & \\
\hline Decrease wealth $<10 \%$ & $0.379 * * *$ & $0.379 * * *$ & 0.364 & $* * *$ \\
\hline Decrease wealth $10 \%$ to $29 \%$ & $0.395 * * *$ & $0.406 * * *$ & 0.443 & $* * *$ \\
\hline Decrease wealth $30 \%$ to $50 \%$ & $0.733 * * *$ & $0.761 * * *$ & 0.800 & $* * *$ \\
\hline Decrease wealth $>50 \%$ & $0.733 * * *$ & $0.763 * * *$ & 0.792 & $* * *$ \\
\hline Same (reference) & - & - & - & \\
\hline \multicolumn{5}{|l|}{ Employment Status } \\
\hline Unemployed and Looking for work & $0.218 * * *$ & $0.267 * * *$ & 0.195 & $* * *$ \\
\hline Not Unemployed (reference) & -- & - & - & \\
\hline Female & -0.005 & 0.029 & 0.080 & $*$ \\
\hline \multicolumn{5}{|l|}{ Age } \\
\hline 16 to 24 & $0.473 \ldots *$ & $0.485 \ldots * *$ & 0.634 & *** \\
\hline 25 to 34 & $0.352 * *$ & $0.337 * *$ & 0.395 & * \\
\hline 35 to 49 & $0.202 * * *$ & $0.204 * *$ & 0.233 & $* * *$ \\
\hline 50 to 65 (reference) & - & -- & - & \\
\hline \multicolumn{5}{|l|}{ Education } \\
\hline Some College & 0.026 & 0.019 & -0.024 & \\
\hline College & $-0.117 *$ & $-0.132 *$ & -0.168 & * \\
\hline Graduate & -0.184 & -0.220 & -0.185 & \\
\hline High School or Less (reference) & -- & -- & -- & \\
\hline \multicolumn{5}{|l|}{ Income } \\
\hline$\sim 0$ to 25 th percentile & $0.238 \cdots *$ & $0.234 \cdots * *$ & 0.180 & * \\
\hline$\sim 25$ th - 50th percentile & $0.281 \cdots$ & $0.268 \cdots *$ & 0.189 & $*$ \\
\hline$\sim 50$ th -75 th percentile & $0.126 * * *$ & $0.134 * * *$ & 0.051 & \\
\hline$\sim 75$ th to 100 th percentile (reference) & - & - & - & \\
\hline \multicolumn{5}{|l|}{ Wealth } \\
\hline$\sim 0$ to 30th percentile & $0.302 *$ & $0.386 * *$ & 0.405 & * \\
\hline$\sim 30$ th -60 th percentile & $0.278 *$ & $0.341 *$ & 0.331 & * \\
\hline 60th - 90th pecentile & $0.208 *$ & $0.246 * * *$ & 0.260 & $* * *$ \\
\hline 90th - 100th percentile (reference) & - & - & - & \\
\hline \multicolumn{5}{|l|}{ Indicators for Missing Values } \\
\hline DK/REF Income Question & -. & 0.057 & -. & \\
\hline DK/REF Financial Wealth Question & $\cdots$ & 0.125 & $\cdots$ & \\
\hline DK/REF Change in Wealth Question & $\cdots$ & 0.091 & $\cdots$ & \\
\hline DK/REF Employment Status Question & - & 0.090 & -- & \\
\hline Constant & $-2.296 * * *$ & $-2.282 * * *$ & -2.338 & $* * *$ \\
\hline N & 4488 & 4405 & 2760 & \\
\hline \multicolumn{5}{|l|}{$* p<0.05, * * p<0.01, \cdots p<0.001$} \\
\hline \multicolumn{5}{|l|}{ Notes: } \\
\hline \multicolumn{5}{|c|}{$\begin{array}{l}\text { 1. Model [1] presents probit coefficients from the model run on a sample for which missing values were } \\
\text { imputed using multiple imputation. The outcome variable was used in the imputation process, but only } \\
\text { cases for which there was non-missing data on the outcome variable were included in the regression } \\
\text { model. }\end{array}$} \\
\hline \multicolumn{5}{|c|}{$\begin{array}{l}\text { 2. Model [2] presents probit coefficients from the baseline regression results as reported in Exhibit } 4 \text { of } \\
\text { the paper. The model is run on a sample for which there is complete data on gender, age, and education. } \\
\text { Dummy variables are included for cases in which there is missing data on income, wealth, changes in } \\
\text { wealth, and unemployent. }\end{array}$} \\
\hline \multicolumn{5}{|c|}{$\begin{array}{l}\text { 3. Model [3] presents probit coefficients from the model run on a sample for which all cases have } \\
\text { complete, non-missing information. }\end{array}$} \\
\hline 4. Standard errors are adjusted for clustering at th & e country-level. & & & \\
\hline 5. All models exclude all Canadian respondents bec & cause no unemployr & ent data is ava & for Canas & \\
\hline
\end{tabular}


Exhibit T2: Complete Model Results of Relationship Between Reduction in Routine Medical Care Following the Crisis and Changes in Wealth and Unemployment, Marginal Effects from Probit Regression, United States, Great Britain, Canada, France, and Germany (Authors' calculations from the TNS Global Economic Crisis Survey, 2009)

\begin{tabular}{|c|c|c|c|c|}
\hline \multirow{2}{*}{$\frac{\text { Explanatory Variables }}{\text { Country-Level Fixed Effects }}$} & \multicolumn{2}{|l|}{ [1] } & \multicolumn{2}{|l|}{ [2] } \\
\hline & & & & \\
\hline United States & 0.160 & *.** & 0.164 & $\cdots$ \\
\hline France & $0.045 *$ & $* * *$ & 0.046 & *** \\
\hline Germany & $0.038 *$ & $* * *$ & 0.039 & $* * *$ \\
\hline Canada & $-0.030 *$ & $* * *$ & -- & \\
\hline Great Britain (reference) & -- & & - & \\
\hline \multicolumn{5}{|l|}{ Change in Wealth Since Crisis } \\
\hline Increase wealth $>10 \%$ & 0.016 & & 0.005 & \\
\hline Increase wealth $<10 \%$ & 0.030 & & 0.024 & \\
\hline Decrease wealth $<10 \%$ & 0.096 & **** & 0.099 & $* * *$ \\
\hline Decrease wealth $10 \%$ to $29 \%$ & 0.108 & $* \approx * *$ & 0.106 & $* * *$ \\
\hline Decrease wealth $30 \%$ to $50 \%$ & $0.233 *$ & $* * *$ & 0.229 & $* * *$ \\
\hline Decrease wealth $>50 \%$ & $0.249 *$ & $* * *$ & 0.231 & *** \\
\hline Same (reference) & - & & -- & \\
\hline \multicolumn{5}{|l|}{ Employment Status } \\
\hline Unemployed and Looking for work & - & & 0.067 & $* * *$ \\
\hline Not Unemployed (reference) & -- & & -- & \\
\hline Female & 0.002 & & 0.007 & \\
\hline \multicolumn{5}{|l|}{ Age } \\
\hline 16 to 24 & $0.117 *$ & $* * *$ & 0.129 & *** \\
\hline 25 to 34 & $0.068 *$ & ** & 0.084 & ** \\
\hline 35 to 49 & $0.046 *$ & $* * *$ & 0.048 & $* *$ \\
\hline 50 to 65 (reference) & -- & & -- & \\
\hline \multicolumn{5}{|l|}{ Education } \\
\hline Some College & -0.003 & & 0.004 & \\
\hline College & -0.026 & $* * *$ & -0.029 & $* *$ \\
\hline Graduate & -0.033 & & -0.044 & \\
\hline High School or Less (reference) & -- & & -- & \\
\hline \multicolumn{5}{|l|}{ Income } \\
\hline$\sim 0$ to 25 th percentile & 0.057 & $* * *$ & 0.056 & $* *$ \\
\hline$\sim 25$ th - 50th percentile & $0.059 \times$ & $* * *$ & 0.065 & $* * *$ \\
\hline$\sim 50$ th - 75th percentile & 0.020 & & 0.032 & *** \\
\hline$\sim 75$ th to 100 th percentile (reference) & - & & -- & \\
\hline \multicolumn{5}{|l|}{ Wealth } \\
\hline$\sim 0$ to 30 th percentile & $0.079 *$ & $* *$ & 0.098 & $* *$ \\
\hline$\sim 30$ th - 60th percentile & $0.060 *$ & * & 0.084 & * \\
\hline 60th - 90th pecentile & $0.046 *$ & $* * *$ & 0.059 & *** \\
\hline 90th - 100th percentile (reference) & -. & & $-\cdot$ & \\
\hline \multicolumn{5}{|l|}{ Indicators for Missing Values } \\
\hline DK/REF Income Question & 0.008 & & 0.013 & \\
\hline DK/REF Financial Wealth Question & 0.027 & & 0.030 & \\
\hline DK/REF Change in Wealth Question & 0.032 & * & 0.021 & \\
\hline DK/REF Employment Status Question & -- & & 0.021 & \\
\hline Pseudo R-Squared & 0.130 & & 0.119 & \\
\hline $\mathrm{N}$ & 5437 & & 4405 & \\
\hline \multicolumn{5}{|l|}{$* p<0.05, * * p<0.01, * * p<0.001$} \\
\hline \multicolumn{5}{|c|}{ Notes: } \\
\hline \multicolumn{5}{|c|}{ 1. Standard errors are adjusted for clustering at the country-level. } \\
\hline \multicolumn{5}{|c|}{ 2. Regressions are estimated using individual sample weights. } \\
\hline \multicolumn{5}{|c|}{$\begin{array}{l}\text { 3. Sample limited to respondents with complete data on the dependent variable, age, } \\
\text { education, and gender. Dichotomous indicators are included for respondents missing } \\
\text { data on income, wealth, and changes in wealth. }\end{array}$} \\
\hline $\begin{array}{l}\text { 4. Model } 2 \text { excludes all Canadian respondents becau } \\
\text { available for Canada. }\end{array}$ & e no unemp & nployr & data are & \\
\hline
\end{tabular}


Exhibit T3: Complete Models Results of Relationship Between Reductions in Routine Medical Care (Relative to Same) and Increases in Routine Medical Care (Relative to Same) and Changes in Wealth and Unemployment, Marginal Effects from Multinomial Probit Regression, United States, France, Germany, and Great Britain (Authors' calculations from the TNS Global Economic Crisis Survey, 2009)

\begin{tabular}{|c|c|c|c|c|}
\hline \multirow{2}{*}{ Explanatory Variables } & \multirow{2}{*}{\multicolumn{2}{|c|}{$\begin{array}{c}\begin{array}{c}\text { Increase } \\
\text { Routine Care } \\
\text { (relative to } \\
\text { Same) }\end{array} \\
{[1]} \\
\end{array}$}} & \multirow{2}{*}{\multicolumn{2}{|c|}{$\begin{array}{c}\begin{array}{c}\text { Decrease } \\
\text { Routine Care } \\
\text { (relative to } \\
\text { Same) }\end{array} \\
{[2]}\end{array}$}} \\
\hline & & & & \\
\hline \multicolumn{5}{|l|}{ Country-Level Fixed Effects } \\
\hline United States & -0.014 & & 0.165 & *... \\
\hline France & -0.031 & $* *$ & 0.045 & $* \approx * *$ \\
\hline Germany & -0.016 * & $* * *$ & 0.039 & $* * *$ \\
\hline Great Britain (reference) & -- & & -. & \\
\hline \multicolumn{5}{|l|}{ Change in Wealth Since Crisis } \\
\hline Increase wealth $>10 \%$ & 0.013 & & 0.003 & \\
\hline Increase wealth $<10 \%$ & 0.022 & & 0.023 & \\
\hline Decrease wealth $<10 \%$ & $0.030 *$ & * & 0.099 & $* * *$ \\
\hline Decrease wealth $10 \%$ to $29 \%$ & 0.004 & & 0.107 & $* * *$ \\
\hline Decrease wealth $30 \%$ to $50 \%$ & 0.012 & & 0.228 & $* * *$ \\
\hline Decrease wealth $>50 \%$ & 0.051 & $* * *$ & 0.231 & $* 2 *$ \\
\hline Same (reference) & $\cdots$ & & $\cdots$ & \\
\hline \multicolumn{5}{|l|}{ Employment Status } \\
\hline Unemployed and Looking for work & 0.000 & & 0.067 & **** \\
\hline Not Unemployed (reference) & -- & & -- & \\
\hline Female & 0.006 & & 0.006 & \\
\hline \multicolumn{5}{|l|}{ Age } \\
\hline 16 to 24 & -0.002 & & 0.129 & **** \\
\hline 25 to 34 & 0.009 & & 0.085 & ** \\
\hline 35 to 49 & 0.004 & & 0.048 & ** \\
\hline 50 to 65 (reference) & - & & -- & \\
\hline \multicolumn{5}{|l|}{ Education } \\
\hline Some College & -0.009 & & 0.004 & \\
\hline College & -0.021 & $*$ & -0.029 & ** \\
\hline Graduate & -0.018 & $* *$ & -0.045 & \\
\hline High School or Less (reference) & -- & & -- & \\
\hline \multicolumn{5}{|l|}{ Income } \\
\hline$\sim 0$ to 25 th percentile & 0.004 & & 0.056 & ** \\
\hline$\sim 25$ th - 50th percentile & 0.013 & & 0.066 & $* * *$ \\
\hline$\sim 50$ th -75 th percentile & 0.001 & & 0.031 & $* * *$ \\
\hline$\sim 75$ th to 100 th percentile (reference) & -- & & -- & \\
\hline \multicolumn{5}{|l|}{ Wealth } \\
\hline$\sim 0$ to 30th percentile & -0.010 & & 0.097 & ** \\
\hline$\sim 30$ th - 60th percentile & -0.015 & & 0.083 & \\
\hline$\sim 60$ th - 90th pecentile & -0.024 & & 0.057 & $* * *$ \\
\hline$\sim 90$ th - 100th percentile (reference) & -- & & - & \\
\hline \multicolumn{5}{|l|}{ Indicators for Missing Values } \\
\hline DK/REF Income Question & -0.001 & & 0.014 & \\
\hline DK/REF Financial Wealth Question & -0.030 & $* *$ & 0.028 & \\
\hline DK/REF Change in Wealth Question & 0.005 & & 0.021 & \\
\hline DK/REF Employment Status Question & 0.017 & & 0.021 & \\
\hline $\mathrm{N}$ & & 440 & & \\
\hline \multicolumn{5}{|l|}{$* p<0.05, * * p<0.01, * * p<0.001$} \\
\hline \multicolumn{5}{|l|}{ Notes: } \\
\hline \multicolumn{5}{|c|}{ 1. Standard errors are adjusted for clustering at the country-level. } \\
\hline \multicolumn{5}{|c|}{ 2. Regressions are estimated using individual sample weights. } \\
\hline \multicolumn{5}{|c|}{$\begin{array}{l}\text { 3. Sample limited to respondents with complete data on the dependent variable, age, education, } \\
\text { and gender. Dichotomous indicators are included for respondents missing data on income, wealth, } \\
\text { and changes in wealth. }\end{array}$} \\
\hline
\end{tabular}


Exhibit T4: Relationship Between Reductions in Routine Medical Care Since the Economic Crisis and Changes in Wealth (Models 1-5) and Unemployment (Models 6-9), by Country for the United States, France, Germany, Canada, and Great Britain, Coefficients from Probit Regression (Authors' calculations from the TNS Global Economic Crisis Survey, 2009)

\begin{tabular}{|c|c|c|c|c|c|}
\hline Explanatory Variables & USA & France & Germany & Canada & Great Britain \\
\hline \multirow{7}{*}{$\begin{array}{l}\text { Change in Wealth } \\
\text { incr }>=10 \% \\
\text { incr }<10 \% \\
\text { decr }<10 \% \\
\text { decr } 10 \% \text { to } 29 \% \\
\text { decr } 30 \% \text { to } 50 \% \\
\text { decr }>50 \%\end{array}$} & [1] & [2] & [3] & [4] & [5] \\
\hline & -0.114 & 0.209 & 0.403 & $0.606 *$ & -0.154 \\
\hline & 0.157 & 0.247 & 0.142 & 0.480 & -0.832 \\
\hline & $0.395 * * *$ & $0.540 \times$ & $0.579 *$ & $0.572 *$ & 0.127 \\
\hline & $0.487^{* * *}$ & $0.712 * * *$ & 0.172 & $0.834^{* * *}$ & -0.036 \\
\hline & $0.811_{* * *}$ & $1.154 * * *$ & $0.704 *$ & $1.241_{* * * *}$ & 0.510 \\
\hline & $0.869 * * *$ & $0.963=* *$ & $0.956 * *$ & $1.355 * * *$ & 0.152 \\
\hline \multirow{2}{*}{ Unemployed } & [6] & [7] & [8] & \multirow{2}{*}{--} & [9] \\
\hline & $0.239 *$ & $0.467 \approx *$ & 0.228 & & 0.278 \\
\hline
\end{tabular}

$* p<0.05, * * p<0.01, * * p<0.001$

Notes:

1. All models include controls for age, income, wealth, gender, and country.

2. Regressions are estimated using individual sample weights.

3. Each sample limited to respondents with complete data on the dependent variable, age, education, and gender. Dichotomous indicators are included for respondents missing data on income, wealth, and changes in wealth. 
Exhibit T5: Relationship Between Reductions in Routine Since the Economic Crisis and Changes in Wealth and Unemployment, Including Interactions between USA and Key Covariates, Coefficients from Probit Regression, United States, France, Germany, and Great Britain (Authors' calculations from the TNS Global Economic Crisis Survey, 2009)

\begin{tabular}{|c|c|c|}
\hline Explanatory Variables & Model 1 & \\
\hline \multicolumn{3}{|l|}{ Country-Level Fixed Effects } \\
\hline United States & 0.517 & $* * *$ \\
\hline \multicolumn{3}{|l|}{ Change in Wealth Since Crisis } \\
\hline Increase wealth $>10 \%$ & 0.205 & * \\
\hline Increase wealth $<10 \%$ & 0.061 & \\
\hline Decrease wealth $<10 \%$ & 0.375 & $* * *$ \\
\hline Decrease wealth $10 \%$ to $29 \%$ & 0.270 & \\
\hline Decrease wealth $30 \%$ to $50 \%$ & 0.770 & $* * *$ \\
\hline Decrease wealth $>50 \%$ & 0.643 & $*$ \\
\hline \multicolumn{3}{|l|}{ Change in Wealth Since Crisis $x$ USA } \\
\hline Increase wealth $>10 \% \times$ USA & -0.329 & *** \\
\hline Increase wealth $<10 \% \times$ USA & 0.081 & \\
\hline Decrease wealth $<10 \% \times$ USA & 0.009 & \\
\hline Decrease wealth $10 \%$ to $29 \% \times$ USA & 0.202 & \\
\hline Decrease wealth $30 \%$ to $50 \% \times$ USA & 0.004 & \\
\hline Decrease wealth $>50 \% \times$ USA & 0.195 & \\
\hline \multicolumn{3}{|l|}{ Employment Status } \\
\hline Unemployed and Looking for work & 0.312 & *** \\
\hline Unemployed and Looking for Work $x$ USA & -0.071 & \\
\hline Constant & -2.130 & $* * *$ \\
\hline $\mathrm{N}$ & 4405 & \\
\hline
\end{tabular}

$* p<0.05, * * p<0.01, * * p<0.001$

Notes:

1. The model includes controls for age, income, wealth, gender, and country

2. Standard errors are adjusted for clustering at the country-level.

3. Regressions are estimated using individual sample weights.

4. Sample limited to respondents with complete data on the dependent variable, age, education, and gender. Dichotomous indicators are included for respondents missing data on income, wealth, and changes in wealth.

5. Model 2 excludes all Canadian respondents because no unemployment data are available for Canada. 